\title{
Allergen-specific immunotherapy for local allergic rhinitis: a systematic review and meta-analysis*
}

\author{
Minh P. Hoang 1,2,3, Jompol Samuthpongtorn ${ }^{4}$, Wirach Chitsuthipakorn ${ }^{5,6}$, \\ Kachorn Seresirikachorn ${ }^{1,2}$, Kornkiat Snidvongs ${ }^{1,2}$ \\ ' Department of Otolaryngology, Faculty of Medicine, Chulalongkorn University, Bangkok, Thailand \\ 2 Endoscopic Nasal and Sinus Surgery Excellent Center, King Chulalongkorn Memorial Hospital, Bangkok, Thailand \\ ${ }^{3}$ Department of Otolaryngology, Hue University of Medicine and Pharmacy, Hue University, Vietnam \\ ${ }^{4}$ Department of Anatomy, Faculty of Medicine, Chulalongkorn University, Bangkok, Thailand \\ ${ }^{5}$ Center of Excellence in Otolaryngology-Head \& Neck Surgery, Rajavithi Hospital, Bangkok, Thailand \\ ${ }^{6}$ Department of Otolaryngology, College of Medicine, Rangsit University, Bangkok, Thailand
}

Rhinology 60: 1, 11 - 19, 2022

https://doi.org/10.4193/Rhin21.193

* Received for publication:

June 4, 2021

Accepted: September 2, 2021

\begin{abstract}
Background: Local allergic rhinitis (LAR) is a phenotype of chronic rhinitis exhibiting a local Th2-driven inflammation without positive clinical markers of atopy. Immunomodulatory effects of allergen-specific immunotherapy (AIT) induce allergen-specific tolerance. However, AIT is not well-recognized as a treatment for LAR.

Methodology: Systematic search on six electronic databases and registries was performed. Experimental and observational studies of AIT for LAR patients were retrieved. The primary outcomes were symptom score, medication score, combined symptom medication score, and disease-specific quality of life. Secondary outcomes were serum specific(s) IgG4, slgE, and adverse events.

Results: Four double-blind randomized controlled trials (156 patients) from two research units assessed the effects of subcutaneous immunotherapy (SCIT). Compared with placebo, SCIT showed significant reductions in symptom score, medication score, combined symptom medication score, disease-specific quality of life, and an increase in serum slgG4. There was no significant change in serum slgE. Likewise, two observational studies (one using SCIT and one using sublingual immunotherapy) improved post-therapeutic symptom score. No studies assessed the effects after discontinuation of treatment. AIT was safe without serious adverse events.
\end{abstract}

Conclusion: AIT has beneficial effects and safe for LAR. Its effects are restricted to studies with short-term follow-up. AIT may be considered in LAR patients.

Key words: allergen, local allergic rhinitis, immunotherapy, subcutaneous, sublingual

\section{Introduction}

Chronic rhinitis is an inflammatory condition of the nasal mucosa, which is classified into allergic rhinitis (AR) and nonallergic rhinitis $(N A R)^{(1)}$. AR is associated with immunoglobulin $E$ (IgE)-mediated response via the Th2 inflammatory pathway after exposure to inhalant allergens ${ }^{(2)}$. Clinical tests for atopy are used to confirm the diagnosis of AR, including skin prick test (SPT) and serum specific(s) lgE. At least one of these two markers of atopy are positive in AR patients ${ }^{(2)}$. Chronic rhinitis patients with negative for both markers are diagnosed with NAR. One-quarter of NAR patients have positive nasal allergen provocation test $(\mathrm{NAPT})^{(3)}$. This condition indicates a localized allergic condition or entopy ${ }^{(3-6)}$. Although the concept of local allergy in the absence of systemic atopy was postulated for the first time in $1975^{(7)}$, the term local allergic rhinitis (LAR) was recognized after better understanding of local mucosal allergic immune reaction without systemic response ${ }^{(5,8,9)}$. However, there are controversies regarding the inconsistency of local slgE detection in patients with $N A R^{(10)}$. In addition, some studies found the transformation from LAR to AR after years of follow-up. As a result, the concept 
of LAR was challenged ${ }^{(11-13)}$.

LAR, also known as entopic rhinitis ${ }^{(5)}$, is a new distinct phenotype exhibiting the Th2-driven inflammatory response, a prominent local allergic response to aeroallergens, such as house dust mites, grass and olive pollens, and molds ${ }^{(8,9)}$. Clinical features of LAR include moderate-to-severe nasal symptoms, an association with asthma or conjunctivitis, and worsening severity over time ${ }^{(4,13)}$. Environmental control and symptomatic treatment, such as oral antihistamine and intranasal corticosteroids, are recommended in daily practice ${ }^{(4,6)}$. Nevertheless, neither allergen avoidance nor symptomatic treatment can ease the clinical worsening and alter the progression of comorbidities ${ }^{(13)}$. To avoid the negative impact of LAR, the treatment is established following putative immunological mechanisms.

Immunomodulatory effects of allergen-specific immunotherapy (AIT) induce allergen-specific tolerance. Therefore, AIT can be indicated for AR or asthma patients who had inadequate benefits from pharmacotherapy ${ }^{(2,14)}$. As AR and LAR share several immunologic similarities ${ }^{(7-9,15)}$, researchers aim to assess the potential of AIT for treating LAR patients ${ }^{(4,6)}$. However, this management is still not well-recognized. In addition, there is a lack of systematic reviews and meta-analyses evaluating the efficacy of AIT with seasonal or perennial allergens on LAR. This systematic review aimed to assess the current evidence of clinical trials investigating the therapeutic role of AIT on LAR. The main objective of this study was to evaluate the efficacy and safety of AIT regarding clinical outcomes and immunological markers for treating LAR. The second objective was to investigate the impact of the type of allergens and the age of study participants on the immunomodulatory effects of AIT.

\section{Materials and methods}

The study protocol was registered on PROSPERO under the identification number of CRD42021233645. The study screening process and selection process were conducted and reported according to the Preferred Reporting Items for Systematic Reviews and Meta-Analyses (PRISMA) guidelines ${ }^{(16)}$.

\section{Search strategy}

Electronic searches on PubMed, EMBASE, ClinicalTrials.gov, Web of Science, Scopus, HTA, and Cochrane Library were performed. ClinicalTrial.gov was searched to collect unpublished data. The last search was 22 July 2021. A manual reference search was performed to retrieve missed relevant studies. For more details of the search strategy, see Table S1 in the Supplement.

\section{Eligibility criteria}

Experimental (randomized-controlled trials (RCTs) or non RCTs) and observational (case-control, cohort) studies of AIT in LAR patients were included. The inclusion criteria of the study participants were 1 ) adult and children with any age, 2) clinical symptoms characteristic of perennial or seasonal rhinitis, 3) a positive NAPT, 4) negative SPT, and 5) negative serum slgE ${ }^{(4)}$. The exclusion criteria were 1) allergic rhinitis, 2) chronic rhinosinusitis, 3) acute rhinosinusitis, 4) cystic fibrosis, 5) immunotherapy started within the prior year, and 6) aspirin-exacerbated respiratory disease. Protocols of AIT with any route, type of specific allergen, dosage, treatment duration, and follow-up period were accepted. Randomized controlled trials (RCTs) that assessed the effects of AIT compared with either placebo or standard pharmacotherapy (oral antihistamines or intranasal corticosteroids) for LAR were eligible for the assessment of AIT effectiveness. Quasi-randomized controlled trials and crossover RCTs were included. All clinical studies with any study design were eligible for the assessment of AIT safety. Reviews, meeting abstracts, and comments were excluded.

\section{Study selection process and data extraction}

Two review authors (MPH and JS) undertook the title and abstract screening based on the prespecified criteria. The full texts of screened studies were assessed for eligibility. Two authors (MPH and KSe) separately extracted the data from the included studies. When there was insufficient information for extraction or imputation, the corresponding author of that study was contacted for more information. Any conflicts during screening and extraction were resolved by discussion among the authors or with the final decision by the corresponding author (KSn). Data extraction was performed and followed the predefined information sheet. The extracted data included patient characteristics, AIT and control group interventions, treatment duration, followup period, and outcome measures. The effects of AIT were categorized as either short-term or long-term. The effects $\leq$ one year after discontinuation of AIT or during treatment were defined as short-term effects. The effects greater than one year after discontinuation of AIT were regarded as long-term effects ${ }^{(17)}$.

\section{Outcome measures}

In accordance with the European Academy of Allergy and Clinical Immunology and the Food and Drug Administration recommendations, the primary outcomes of AIT were combined symptom and medication score (CSMS), symptom score (SS), medication score (MS), and disease-specific quality of life (QoL) (18). Secondary outcomes were serum slgG4, serum slgE, and adverse events. Adverse events were classified as local reaction, systemic reaction, anaphylaxis, and death.

\section{Risk of bias in individual studies}

Two review authors (MPH and JS) independently assessed risk of bias of the included RCTs following the Cochrane Collaboration's tool ${ }^{(19)}$. There were seven domains in terms of random sequence generation, allocation concealment, blinding of participants and personnel, blinding of outcome assessment, incomplete 


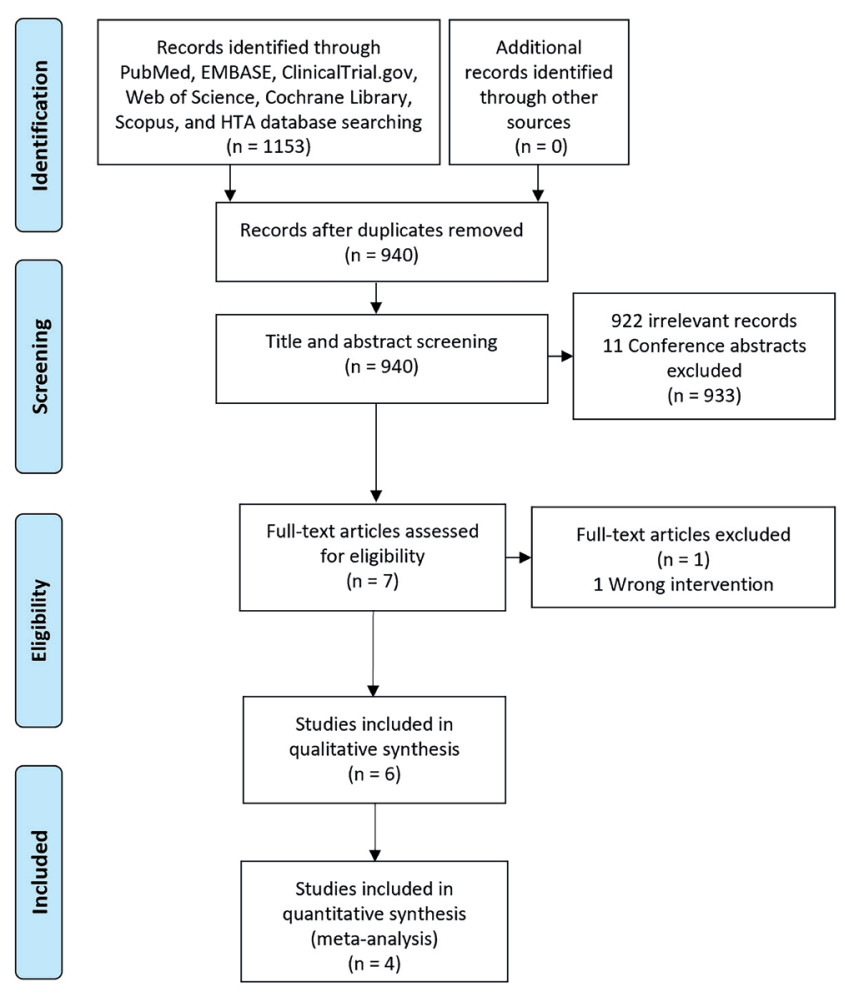

Figure 1. Flow diagram of study selection followed the Preferred Reporting Items for Systematic Reviews and Meta-Analyses (PRISMA) guidelines.

outcome data, selective outcome reporting, and other bias. Each domain was assessed and expressed as "low risk" when the domain had a clear explanation of the method, "high risk" when the respective domain had not been mentioned, or "unclear risk" when the domain was mentioned but inadequately described. Quality assessment of the non-randomized controlled trials used the methodological index for non-randomized studies (MINORS) with eight domains for non-comparative studies or 12 domains for comparative studies(20). Individual domains were scored from 0 to 2 . A total score of the non-comparative studies below 11 and the comparative studies below 16 represented high risk of bias.

Data synthesis and statistical analysis

Data were pooled for meta-analysis. The risk of adverse events was presented as risk ratio (RR) and $95 \%$ confidence interval (Cl). Mean difference (MD) or standardized mean difference (SMD) with standard deviation (SD) and 95\% Cl were calculated to assess continuous outcomes. If the change from baseline to endpoint was not available, the final score was extracted. The standard error, interquartile range, and $95 \% \mathrm{Cl}$ were interpreted if the SD was not reported ${ }^{(21)}$. Discrepancies in treatment effects among different trials were assessed using heterogeneity $\left(\mathrm{I}^{2}\right)$ statistic. An $\mathrm{I}^{2}$ of $<40 \%, 40-60 \%$ and $>60 \%$ represented low, moderate and substantial heterogeneity, respectively. When the heterogeneity was low, a fixed-effect model was used. A random- effects model was used if the heterogeneity was high for a more conservative estimate of the differences. Subgroup analyses by characteristic of rhinitis symptoms, age of the participants, and study quality were conducted. Studies with any high risks of bias were grouped as "Low-quality study". Funnel plot was used to assess publication bias. Egger's test was used to measure smallstudy effects for quantitative syntheses of at least ten studies. All statistical assessments were performed using Review Manager (RevMan) version 5.4.1 ${ }^{(22)}$.

\section{Results}

Study selection

A total of 1153 studies were retrieved after the initial search. After removing duplicate studies, the remaining 940 articles underwent title and abstract screening. Full texts of 7 articles were assessed for eligibility. Finally, six studies were selected for qualitative synthesis (4 RCTs ${ }^{(23-26)}$ and two observational stu$\left.\operatorname{dies}^{(27,28)}\right)$, of which four RCTs were included in the meta-analysis. Neither quasi-randomized controlled trial nor crossover RCT was found. Figure 1 displays the study selection process according to PRISMA.

\section{Participants}

There were 236 participants with the mean age ranging from 23.8 to 39.9 years. One hundred and thirty-nine participants (58.9\%) were female. One study recruited patients under 15 years of age ${ }^{(28)}$. Three RCTs ${ }^{(24-26)}$ and one comparative observational study ${ }^{(27)}$ assessed LAR with seasonal rhinitis symptoms. One $\mathrm{RCT}^{(23)}$ and one non-comparative observational study ${ }^{(28)}$ assessed LAR with perennial rhinitis symptoms. Asthma and conjunctivitis were the common comorbidities with the proportion of $36.73 \%^{(23,25-27)}$ and $70.27 \%^{(23,25,27)}$, respectively. Table 1 shows characteristics of the included studies.

\section{Intervention}

Sublingual immunotherapy (SLIT) and subcutaneous immunotherapy (SCIT) were used in one ${ }^{(28)}$ and five ${ }^{(23-27)}$ studies, respectively. Allergen extracts administrated in the included studies consisted of pollen extracts ${ }^{(24-27)}$, Dermatophagoides pteronys$\sin ^{(27)}$, and Dermatophagoides farinae ${ }^{(28)}$. Aluminum-containing adjuvants were used in all five SCIT studies ${ }^{(23-27)}$. No study assessed the effects after discontinuation of treatment.

\section{Comparisons}

Four RCTs compared SCIT with placebo ${ }^{(23-26)}$. One observation study compared SCIT with rescue medication (oral antihistamine, intranasal and oral corticosteroid) ${ }^{(27)}$. One non-comparative observational study assessed the efficacy and safety of SLIT (28).

\section{Short-term outcomes}

Combined symptom and medication score (CSMS) 


\begin{tabular}{|c|c|c|c|c|c|c|c|c|c|}
\hline $\begin{array}{l}\text { First Author, } \\
\text { Year }\end{array}$ & $\begin{array}{l}\text { Study } \\
\text { Design }\end{array}$ & $\begin{array}{l}\text { Patient } \\
\text { (n) }\end{array}$ & $\begin{array}{c}\text { Female } \\
(\%)\end{array}$ & $\begin{array}{l}\text { Mean } \\
\text { Age } \\
\text { (years) }\end{array}$ & Allergy & AIT & Control & Outcomes & $\begin{array}{l}\text { Duration } \\
\text { (months) }\end{array}$ \\
\hline Rondon ${ }^{(27)}, 2011$ & Cohort & 20 & 75.0 & 31.1 & $\begin{array}{l}\text { Grass mix } \\
\text { pollen }\end{array}$ & SCIT & $\begin{array}{l}\text { Medication } \\
\text { only }\end{array}$ & SS, MS, MFD, slgG4, slgE, NAPT & 6 \\
\hline Rondon ${ }^{(23)}, 2016$ & DBRCT & 36 & 75.0 & 39.9 & DP & SCIT & Placebo & $\begin{array}{c}\text { CSMS, SS, MS, MFD, slgG4, slgE, } \\
\text { NAPT }\end{array}$ & 24 \\
\hline Bozek ${ }^{(24)}, 2018$ & DBRCT & 29 & 48.3 & 23.8 & $\begin{array}{l}\text { Betula } \\
\text { verrucosa }\end{array}$ & SCIT & Placebo & $\begin{array}{c}\text { CSMS, SS, MS, RQLQ, slgG4, slgE, } \\
n s l g E\end{array}$ & 24 \\
\hline Rondon ${ }^{(25)}, 2018$ & DBRCT & 55 & 63.6 & 38.3 & $\begin{array}{l}\text { Phleum } \\
\text { pratense }\end{array}$ & SCIT & Placebo & $\begin{array}{c}\text { CSMS, SS, MS, MFD, NS, OS, BS, } \\
\text { RQLQ, slgG4, slgE }\end{array}$ & 24 \\
\hline Yin ${ }^{(28)}, 2019$ & Cohort & 60 & 41.6 & 39.5 & DF & SLIT & None & $\begin{array}{c}\text { SS, VAS of severity symptoms, NAPT, } \\
\text { nslgE }\end{array}$ & 36 \\
\hline Bozek ${ }^{(26)}, 2020$ & DBRCT & 36 & 63.9 & 26.4 & $\begin{array}{l}\text { Betula } \\
\text { verrucosa }\end{array}$ & SCIT & Placebo & $\begin{array}{c}\text { CSMS, SS, MS, RQLQ, slgG4, slgE, } \\
\text { BAPT }\end{array}$ & 36 \\
\hline
\end{tabular}

DBRCT, double-blind randomized controlled trial; AIT, allergen-specific immunotherapy; SCIT, subcutaneous immunotherapy; SLIT, sublingual immunotherapy; SS, symptom score; MS, medication score; CSMS, combined symptom medication score; MFD, medication free days; NS, nasal score; OS ocular score; BS, bronchial score; RQLQ, Rhinoconjunctivitis Quality of Life Questionnaire; NAPT, nasal allergen provocation test; BAPT, bronchial allergen provocation test; slgG4, serum specific immunoglobulin G4; slgE, serum specific immunoglobulin E; nslgE, nasal specific immunoglobulin E; DP, Dermatophagoides pteronyssinus; DF, Dermatophagoides farinae.

Four RCTs compared the improvement in CSMS between SCIT and placebo ${ }^{(23-26)}$. The effect on CSMS reduction favored SCIT over placebo (SMD -2.88; $95 \% \mathrm{Cl}-4.55,-1.21 ; \mathrm{p}<0.01)$. An $\mathrm{I}^{2}$ of $92 \%$ represented substantial heterogeneity. The comparisons of CSMS and forest plot are shown in Figure 2.

\section{Symptom score (SS)}

Four RCTs compared the improvement in SS between SCIT and placebo using different scales (4-point scale ${ }^{(23,25)}$ and visual analogue scale ${ }^{(24,26)}$. The effect on SS reduction favored SCIT over placebo (SMD -2.59; 95\% Cl -3.88, -1.29; $\mathrm{p}<0.01$ ). An $\mathrm{I}^{2}$ of $88 \%$ represented substantial heterogeneity. The comparisons of SS and forest plot are shown in Figure 3. One observational study showed a greater improvement of SS in SCIT group than the rescue medication group ${ }^{(27)}$. The other observational study showed a significant reduction of the post-therapeutic SS, after 3-year treatment with SLIT (28).

\section{Medication score (MS)}

Four RCTs compared the improvement in MS between SCIT and placebo using different scales (maximum score of $3.4^{(23,25)}$ and $\left.6^{(24,26)}\right)$. The effect on MS reduction favored SCIT over placebo (SMD - $1.84 ; 95 \% \mathrm{Cl}-3.10,-0.57 ; \mathrm{p}<0.01)$. An $\mathrm{I}^{2}$ of $92 \%$ represented substantial heterogeneity. The comparisons of MS and forest plot are shown in Figure 4.

\section{Disease-specific quality of life}

Three RCTs assessed improvement in disease-specific QoL between SCIT and placebo in LAR with seasonal rhinitis symptoms ${ }^{(24-26)}$. All of them used the Rhinoconjunctivitis Quality of Life Questionnaire (RQLQ). The effect on improvement of RQLQ favored SCIT over placebo (SMD -1.14; 95\% Cl-1.54,-0.74; $\mathrm{p}<0.01)$. An $\mathrm{I}^{2}$ of $10 \%$ represented low heterogeneity. The comparison of RQLQ and forest plot are shown in Figure 5.

\section{Subgroup analysis by characteristic of rhinitis symptoms} When subgroup analysis by characteristic of rhinitis was conducted (perennial vs. seasonal symptoms), SCIT significantly reduced the CSMS and SS better than placebo in both subgroups (Figure 2-3). There was a significant difference between subgroups in SS improvement $(p<0.01)$, the effect was greater in the seasonal rhinitis subgroup (SMD -3.17; 95\% Cl -4.62, -1.72) compared with the perennial rhinitis subgroup (SMD $-1.01 ; 95 \% \mathrm{Cl}-1.71,-0.31$ ) (Figure 3). Likewise, the effect on MS improvement favored SCIT over placebo was demonstrated only in the seasonal rhinitis symptoms subgroup (SMD -2.31; 95\% $\mathrm{Cl}-4.13,-0.49)$, not the perennial symptoms group (SMD -0.60; $95 \% \mathrm{Cl}-1.27,0.07)$. However, there was no significant difference between the subgroups $(\mathrm{p}=0.08)$ (Figure 4$)$.

\section{Subgroup analysis by the age of participants}

Subgroup analysis by the age of participants was not conducted because none of the included RCTs assessed pediatric subjects. There was only one non-comparative observational study assessing pediatric subjects ${ }^{(28)}$. 


\begin{tabular}{|c|c|c|c|c|c|c|c|c|c|c|c|}
\hline \multirow{3}{*}{$\begin{array}{l}\text { Study or Subgroup } \\
\text { 1.4.1 Perennial LAR }\end{array}$} & \multicolumn{3}{|c|}{ SCIT } & \multicolumn{3}{|c|}{ Placebo } & \multicolumn{3}{|c|}{ Std. Mean Difference } & \multirow{2}{*}{$\begin{array}{l}\text { Std. Mean Difference } \\
\text { IV, Random, } 95 \% \mathrm{Cl}\end{array}$} & Risk of Bias \\
\hline & Mean & SD & Total & Mean & SD & Total & Weight & t IV, Random, $95 \% \mathrm{Cl}$ & Year & & $A B C D E F G$ \\
\hline & & & & & & & & & & & \\
\hline $\begin{array}{l}\text { Rondon } 2016 \\
\text { Subtotal }(95 \% \mathrm{Cl})\end{array}$ & 1.35 & 0.89 & $\begin{array}{l}18 \\
18\end{array}$ & 2.36 & 0.89 & $\begin{array}{l}18 \\
18\end{array}$ & $\begin{array}{l}26.7 \% \\
26.7 \%\end{array}$ & $\begin{array}{l}-1.11[-1.82,-0.40] \\
-1.11[-1.82,-0.40]\end{array}$ & 2016 & 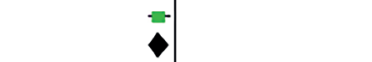 & $+\bullet+\bullet-\oplus+$ \\
\hline \multicolumn{12}{|c|}{ Heterogeneity: Not applicable } \\
\hline \multicolumn{12}{|l|}{ 1.4.2 Seasonal LAR } \\
\hline Bozek 2018 & 2.5 & 0.98 & 15 & 6.36 & 0.83 & 13 & $23.6 \%$ & $-4.10[-5.48,-2.72]$ & 2018 & & $\bullet+\div+\bullet+\bullet$ \\
\hline Rondon 2018 & 1.2 & 0.8 & 26 & 2.6 & 1.2 & 29 & $27.1 \%$ & $-1.34[-1.93,-0.75]$ & 2018 & $-\frac{-1}{-1}$ & \\
\hline $\begin{array}{l}\text { Bozek } 2020 \\
\text { Subtotal }(95 \% \mathrm{Cl})\end{array}$ & 2.09 & 0.45 & $\begin{array}{l}18 \\
59\end{array}$ & 4.81 & 0.51 & $\begin{array}{l}16 \\
58\end{array}$ & $\begin{array}{l}22.6 \% \\
73.3 \%\end{array}$ & $\begin{array}{l}-5.54[-7.10,-3.99] \\
-3.59[-6.29,-0.89]\end{array}$ & 2020 & - & $+\oplus+\oplus+$ \\
\hline \multicolumn{12}{|c|}{$\begin{array}{l}\text { Heterogeneity: } \text { Tau }^{2}=5.31 ; \mathrm{Chi}^{2}=33.28, \mathrm{df}=2(\mathrm{P}<0.00001) ; \mathrm{F}=94 \% \\
\text { Test for overall effect: } Z=2.60(P=0.009)\end{array}$} \\
\hline Total $(95 \% \mathrm{Cl})$ & & & 77 & & & 76 & $100.0 \%$ & $-2.88[-4.55,-1.21]$ & & & \\
\hline \multicolumn{10}{|c|}{$\begin{array}{l}\text { Heterogeneity: } \mathrm{Tau}^{2}=2.58 ; \mathrm{Chi}^{2}=39.02, \mathrm{df}=3(\mathrm{P}<0.00001) ; \mathrm{F}^{2}=92 \% \\
\text { Test for overall effect: } Z=3.38(\mathrm{P}=0.0007) \\
\text { Test for subgroup differences: } \mathrm{Chi}^{2}=3.03, \mathrm{df}=1(P=0.08), \mathrm{F}^{2}=67.0 \%\end{array}$} & $\begin{array}{ccccc}-10 & -5 & 0 & 5 & 10 \\
\text { Favours } & {[\mathrm{SCIT}]} & \text { Favours [Placebo] }\end{array}$ & \\
\hline \multicolumn{12}{|c|}{ Risk of bias legend } \\
\hline \multicolumn{12}{|c|}{$\begin{array}{l}\text { (A) Random sequence generation (selection bias) } \\
\text { (B) Allocation concealment (selection bias) }\end{array}$} \\
\hline $\begin{array}{l}\text { (C) Blinding of partici } \\
\text { (D) Blinding of outcor } \\
\text { (E) Incomplete outco } \\
\text { (F) Selective reportin } \\
\text { (G) Other bias }\end{array}$ & $\begin{array}{l}\text { ants an } \\
\text { le asse } \\
\text { he data } \\
\text { (reporti }\end{array}$ & $\begin{array}{l}\text { a pers } \\
\text { ssmen } \\
\text { (attritio } \\
\text { ng bias }\end{array}$ & $\begin{array}{l}\text { sonnel ( } \\
\text { nt (detec } \\
\text { on bias) } \\
\text { (s) }\end{array}$ & perform & $\begin{array}{l}\text { lance } \\
\text { as) }\end{array}$ & bias) & & Low risk of bias & & Unclear risk of bias & High risk of bias \\
\hline
\end{tabular}

Figure 2. Short-term improvement in combined symptom and medication score and subgroup analysis by characteristic of rhinitis symptoms: subcutaneous immunotherapy versus placebo. SCIT = subcutaneous immunotherapy; $\mathrm{Cl}=$ confidence interval; $\mathrm{df}=$ degrees of freedom; Std. mean difference $=$ standardized mean difference.

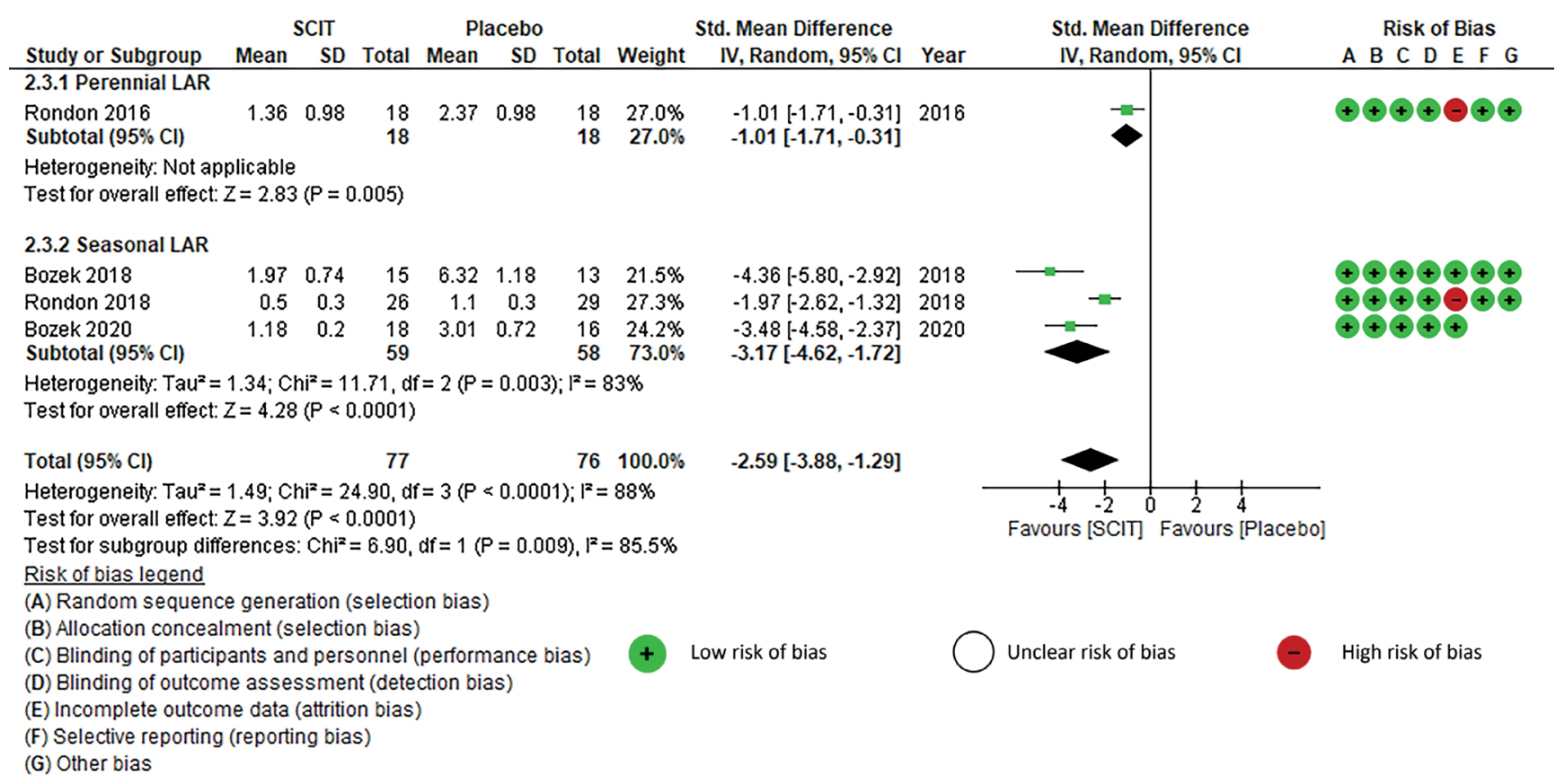

Figure 3. Short-term improvement in symptom score and subgroup analysis by characteristic of rhinitis symptoms: subcutaneous immunotherapy versus placebo. SCIT = subcutaneous immunotherapy; $\mathrm{Cl}=$ confidence interval; $\mathrm{df}=$ degrees of freedom; Std. mean difference = standardized mean difference.

\section{Subgroup analysis by study quality}

When subgroup analysis by study quality was performed (highquality vs. low-quality), SCIT significantly reduced CSMS, SS, and MS better than placebo in both subgroups. SCIT showed a greater magnitude of benefit regarding CSMS, SS, and MS in highquality studies than low-quality studies significantly $(p<0.01)$ in all outcomes (Figures S1-S3).

\section{Serum specific lgG4 level}

Four RCTs assessed serum slgG4 levels between SCIT and placebo ${ }^{(23-26)}$. Data from one RCT were not extracted because the mean and SD were not reported ${ }^{(26)}$. There was no difference 


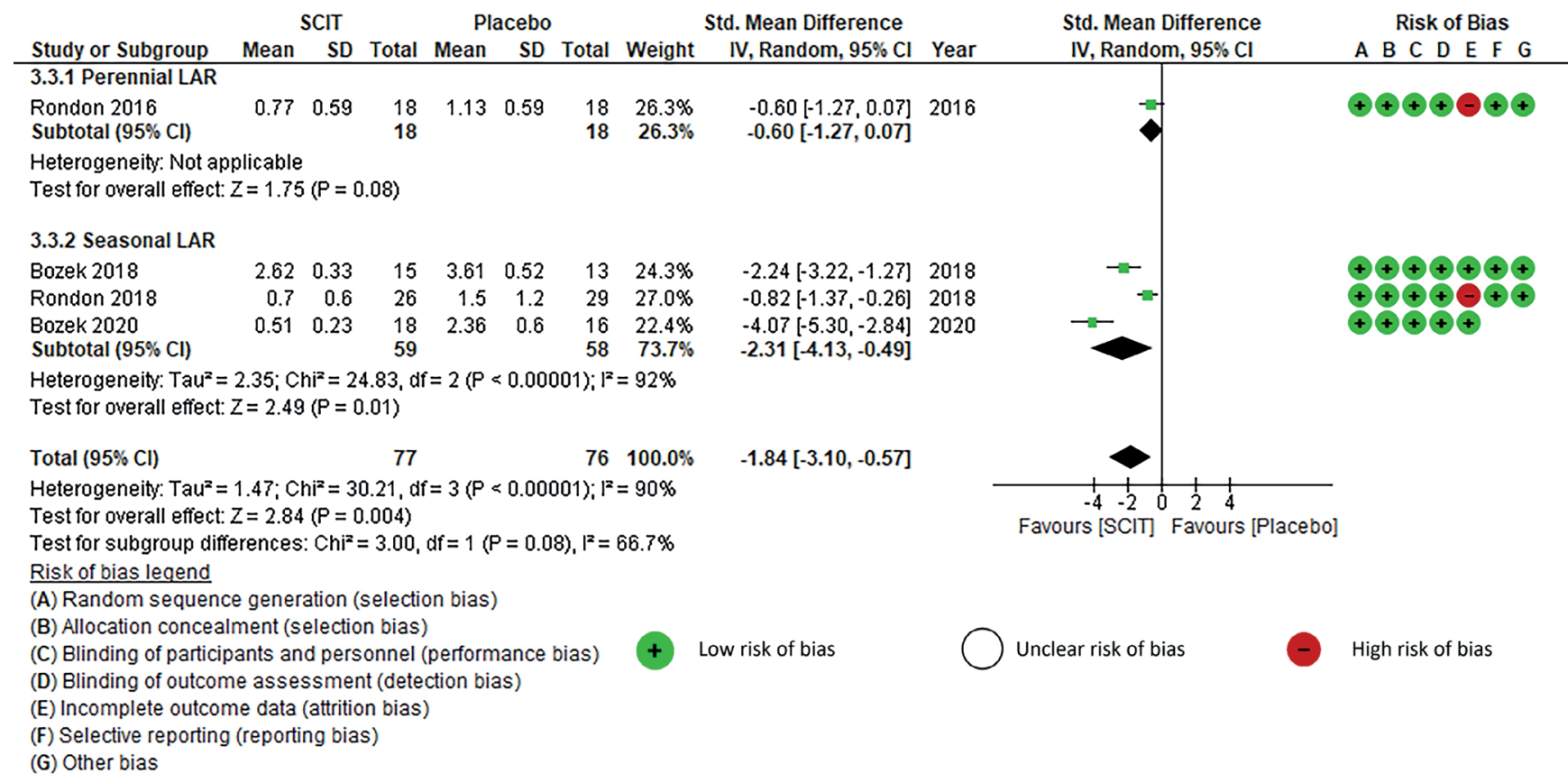

Figure 4. Short-term improvement in medication score and subgroup analysis by characteristic of rhinitis symptoms: subcutaneous immunotherapy versus placebo. SCIT = subcutaneous immunotherapy; $\mathrm{Cl}=$ confidence interval; $\mathrm{df}=$ degrees of freedom; Std. mean difference = standardized mean difference.

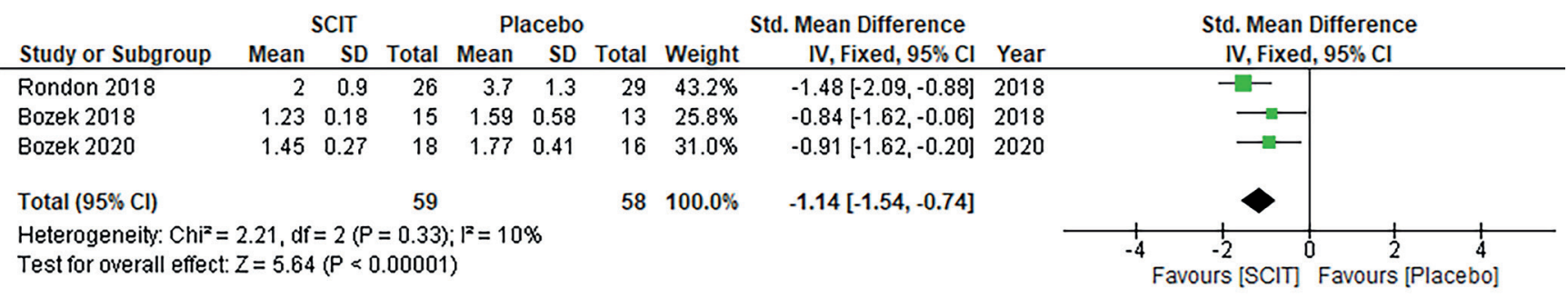

Figure 5. Short-term improvement in Rhinoconjunctivitis Quality of Life Questionnaire: subcutaneous immunotherapy versus placebo. SCIT = subcutaneous immunotherapy; RQLQ = Rhinoconjunctivitis Quality of Life Questionnaire; Cl = confidence interval; df = degrees of freedom; Std. mean difference $=$ standardized mean difference.

in the 1-year effect on increasing slgG4 level (SMD 0.98; $95 \%$ $\mathrm{Cl}-0.49,2.45 ; \mathrm{p}=0.19)$ but the 2-year effect favored SCIT over placebo (SMD 2.84; 95\% Cl 0.43, 5.26; $\mathrm{p}=0.02$ ). $\mathrm{I}^{2}$ of $92 \%$ and $96 \%$ represented substantial heterogeneity, respectively. The comparisons of slgG4 and forest plots are shown in Figure 6. In an observational study ${ }^{(27)}$, a significant increase in slgG4 level after 1-year SCIT was observed.

\section{Serum specific IgE level}

Four RCTs assessed serum slgE levels between SCIT and placebo $^{(23-26)}$, in which slgE levels were not detected in the placebo arm of two RCTs ${ }^{(24,26)}$. Therefore, the data from these two studies could not be pooled for meta-analysis ${ }^{(23,25)}$. There were no differences in the 1-year effect (SMD 0.31; 95\% Cl-0.19, 0.80; $p=0.23$ ) and the 2-year effect (SMD 0.05; 95\% Cl-0.36, 0.46; $\mathrm{p}=0.81$ ). An I of $0 \%$ represented low heterogeneity. No significant change of serum slgE level after 1-year SCIT was observed in one observational study ${ }^{(27)}$.

\section{Long-term outcomes}

None of the studies assessed the effects after discontinuation of treatment.

\section{Adverse events}

All included studies assessed the safety of AIT. There were no significant differences in the risk of local reaction between SCIT and placebo in total participants (RR 2.39; 95\% Cl 0.57, 10.04; $\left.\mathrm{p}=0.23 ; \mathrm{l}^{2}=0 \%\right)^{(23,25)}$ nor in total injections (RR 1.10; $95 \% \mathrm{Cl} 0.65$, 1.87; $p=0.72)^{(24)}$. However, one $\mathrm{RCT}$ reported a higher risk of local reaction in SCIT compared with placebo ${ }^{(26)}$. There was no signifi- 
A

\begin{tabular}{|c|c|c|c|c|c|c|c|c|c|c|}
\hline \multirow{2}{*}{ A } & \multicolumn{3}{|c|}{ Placebo } & \multicolumn{3}{|c|}{ SCIT } & \multicolumn{3}{|c|}{ Std. Mean Difference } & \multirow{2}{*}{$\begin{array}{l}\text { Std. Mean Difference } \\
\text { IV, Random, } 95 \% \mathrm{Cl}\end{array}$} \\
\hline & Mean & SD & Total & Mean & SD & Total & I Weight & IV, Random, $95 \% \mathrm{Cl}$ & Year & \\
\hline Rondon 2016 & 0.13 & 0.34 & 18 & 0.2 & 1.23 & 18 & $3 \quad 34.5 \%$ & $-0.08[-0.73,0.58]$ & 8] 2016 & 학 \\
\hline Bozek 2018 & 0.09 & 0.14 & 13 & 0.8 & 0.27 & 15 & $30.1 \%$ & $-3.14[-4.29,-1.98]$ & 2018 & - \\
\hline Rondon 2018 & 0.01 & 2.06 & 29 & 0.05 & 0.48 & 26 & $35.3 \%$ & $-0.03[-0.56,0.50]$ & ]] 2018 & \\
\hline Total $(95 \% \mathrm{Cl})$ & & & 60 & & & 59 & $9100.0 \%$ & $-0.98[-2.45,0.49]$ & & \\
\hline \multicolumn{10}{|c|}{$\begin{array}{l}\text { Heterogeneity: } \operatorname{Tau}^{2}=1.52 ; \mathrm{Chi}^{2}=24.38, \mathrm{df}=2(\mathrm{P}<0.00001) ; \mathrm{I}^{2}=92 \% \\
\text { Test for overall effect: } Z=1.31(\mathrm{P}=0.19)\end{array}$} & 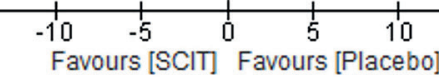 \\
\hline B & \multicolumn{3}{|c|}{ Placebo } & \multicolumn{3}{|c|}{ SCIT } & \multirow{2}{*}{\multicolumn{3}{|c|}{$\begin{array}{l}\text { Std. Mean Difference } \\
\text { Weight } \quad \text { IV, Random, } 95 \% \mathrm{Cl} \quad \text { Year }\end{array}$}} & \multirow{2}{*}{$\begin{array}{l}\text { Std. Mean Difference } \\
\text { IV, Random, } 95 \% \mathrm{Cl}\end{array}$} \\
\hline Study or Subgroup & Mean & SD & Total & Mean & SD & Total & & & & \\
\hline Rondon 2016 & 0.1 & 0.13 & 18 & 0.32 & 0.38 & 18 & $37.9 \%$ & $-0.76[-1.44,-0.08]$ & 2016 & 部 \\
\hline Bozek 2018 & 0.0011 & 0.01 & 13 & 0.89 & 0.11 & 15 & $23.8 \%$ & $-10.65[-13.75,-7.55]$ & 2018 & \\
\hline Rondon 2018 & 0.18 & 2.1 & 29 & 0.32 & 2.25 & 25 & $38.3 \%$ & $-0.06[-0.60,0.47]$ & 2018 & + \\
\hline Total $(95 \% \mathrm{Cl})$ & & & 60 & & & 58 & $100.0 \%$ & $-2.84[-5.26,-0.43]$ & & \\
\hline \multicolumn{10}{|c|}{$\begin{array}{l}\text { Heterogeneity: Tau }{ }^{2}=3.89 ; C h i^{2}=44.30, d f=2(P=0.00001) ; I^{2}=95 \% \\
\text { Test for overall effect: } Z=2.31(P=0.02)\end{array}$} & $\begin{array}{ccccc}-10 & -5 & 0 & 5 & 10 \\
\text { Favours [SCIT] } & \text { Favours [Placebo] }\end{array}$ \\
\hline
\end{tabular}

Figure 6. Change on specific lgG4 level: subcutaneous immunotherapy versus placebo (higher = better). (A) 1 year. (B) 2 years. SCIT = subcutaneous immunotherapy; $\mathrm{Cl}$ = confidence interval; $\mathrm{df}=$ degrees of freedom; $\mathrm{Std}$. mean difference = standardized mean difference.

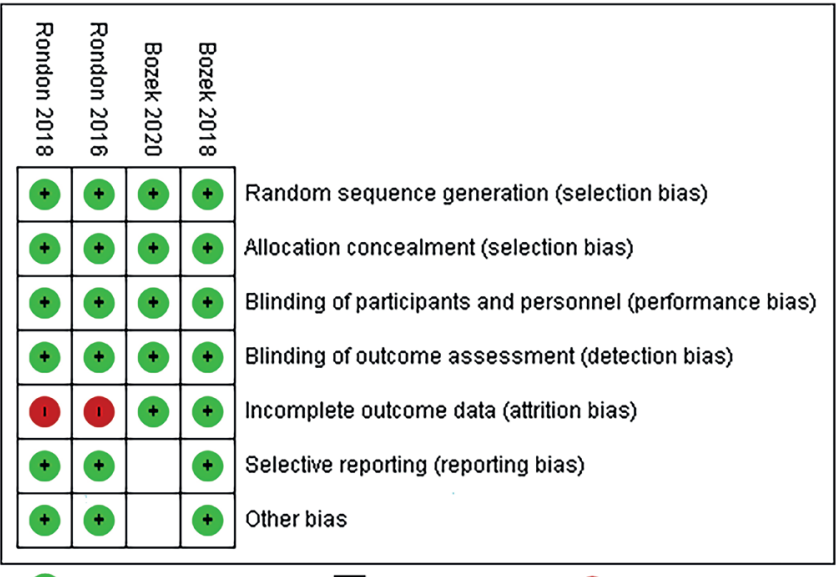

† Low risk of bias

$\square$ Unclear risk of bias (1) High risk of bias

Figure 7. Risk of bias assessment of included RCTs.

cant difference in the risk of systemic reaction between SCIT and placebo (RR 0.87; 95\% Cl 0.06, 12.52; $\mathrm{p}=0.92)^{(24)}$. In two observational studies, one local reaction was reported in one of the 20 patients who used SCIT(27), while 60 participants received 3-year SLIT without adverse events ${ }^{(28)}$.

Quality of the included studies

Four RCTs had low risks of bias in random sequence generation, allocation concealment, blinding of participants and personnel, and blinding of outcome assessment. Two studies by Rondon et al. ${ }^{(24,26)}$ had high risk of bias in incomplete outcome data due to high dropout rate. Bozek et al. ${ }^{(26)}$ reported different outcomes with insufficient data from NCT trial registration. Therefore, we rated them as unclear risks of reporting bias and other bias (Figure 7). One comparative observational study had low risk of bias and one non-comparative study had high risk of bias with total MINORS scores of $21^{(27)}$ and $10^{(28)}$ points, respectively (Table S2). Neither Funnel plot nor Egger's test was performed due to the limited number of the included studies.

\section{Discussion}

LAR is acknowledged as a distinct non-allergic rhinitis subtype associated with Th2 patterns which is characterized by nasal production of slgE antibodies ${ }^{(6)}$, increased eosinophils, $\mathrm{CD}^{+}$ $T$ cells, and $\mathrm{CD}^{+} \mathrm{T}$ cells in the nasal fluid after exposure to allergens ${ }^{(9)}$. The expression of the direct class switch recombination to lgE markers in the nasal B cells indicates the existence of local IgE synthesis and regulation of heavy chain switching to $\operatorname{lgE}$ in the nasal mucosa ${ }^{(15)}$. Rondon et al..$^{(8)}$ used flow cytometry and found a similar nasal leukocyte-lymphocyte phenotype between AR and LAR. There is indirect evidence of Th2 lgEmediated inflammatory response showing that LAR patients have a positive basophil activation test response $\mathrm{e}^{(29,30)}$. With its immunomodulatory effect, AIT can target the immunological mechanism of LAR and change the course of the disease despite the negative SPT and serum slgE tests.

This is the first systematic review and meta-analysis that assessed the efficacy and safety of AIT as a treatment for LAR. Our meta-analysis showed significant short-term beneficial effects of AIT on improving CSMS, SS, MS, RQLQ, and serum slgG4. Subgroup analysis suggests that patients with seasonal LAR have a greater benefit in terms of SS compared to those with perennial, though there was only one study $(n=18)$ in the latter group. The difference in symptoms improvement between the patients with seasonal and perennial LAR may result from discrepancies in symptom severity scales. Bozek et al. ${ }^{(24,26)}$ used a visual analogue scale for assessing seasonal symptoms while perennial symptoms were evaluated by a 4-point scale ${ }^{(23)}$. Noticeably, Th2 inflammation is not the only causative mechanism in all AR. Innate immune, representing as the group 2 innate lymphoid cells 
(ILC2s), is also involved in the development of AR, e.g. in house dust mite-induced $A R^{(31)}$. In contrast to the dominant role of AIT in Th2-acquired immunity, remarkably in pollen-induced AR, AIT has modest effects on ILC2s-influenced $\mathrm{AR}^{(31)}$. Therefore, this indirect evidence may elicit the lesser degree of benefit of AIT for LAR with house-dust-mite allergens.

The immunologic outcomes were steadily changed in the AIT group with a significant increase in slgG4 after two years of treatment, which was not seen in the placebo group. This is in line with a report on immunologic changes after using AIT for $A R^{(32)}$. There were no differences in serum slgE at any time point between AIT and placebo with low heterogeneity. This finding indicates a retained local allergic response without altering systemic slgE. However, two RCTs by Rondon et al. ${ }^{(23,25)}$ reported increased serum slgE levels with positive SPT at the end of the study in some patients of both active and placebo groups. Although still debated, this may be initial evidence that supports the possible transformation from LAR to $A R^{(11)}$.

Interestingly, a gradual decrease in nasal slgE level was seen in the active intervention but not in the placebo group of one study ${ }^{(24)}$. This result demonstrates the suppression of nasal slgE production and the effectiveness of AIT for LAR. In agreement with this finding, Yin et al. ${ }^{(28)}$ also showed a significant decrease in nasal slgE after 3-year treatment with SLIT. However, the finding on nasal slgE is still controversial due to inconsistency among studies ${ }^{(10)}$. The discrepancy of results might be a consequence of environmental and racial diversity.

A significant proportion of patients with LAR had comorbidities such as conjunctivitis and asthma ${ }^{(13,23,25-27)}$. However, it is sometimes difficult to find a relationship between asthma and LAR whether asthma is an independent disease or correlates with LAR as local allergic asthma ${ }^{(26,33)}$. One study demonstrated that the markers of direct class switch recombination to IgE were found in the bronchial mucosa of patients with asthma regardless of atopic condition ${ }^{(33)}$. These markers suggested the local IgE production in lower airways ${ }^{(33)}$. Bozek et al. ${ }^{(26)}$ demonstrated the effect of AIT on improving bronchial responsiveness in five of seven LAR patients who were positive for the bronchial challenge to birch allergen test. This finding suggests that AIT can decrease the comorbidities progression and improve quality of life in LAR patients.

All 4 RCTs and 2 observational studies displayed the safety of AIT, in which no significant risk of systemic reaction of AIT was shown. All but one RCTs showed no difference between the risk of local reaction between AIT and placebo ${ }^{(23-25)}$. Although a higher risk of local reaction in active intervention than placebo was observed in one $\mathrm{RCT}^{(26)}$, this trial used a different product from the others.

Our systematic review and meta-analysis had limitations in several aspects. First, four RCTs were only conducted by two teams in two regions. Thus, they might not represent the effectiveness of AIT in general since the severity of LAR is very heterogeneous in terms of race and environment. Second, the meta-analyses had substantial heterogeneity. Although analyzed by subgroups, a subgroup of patients with seasonal symptoms still had substantial heterogeneity. There is a possibility that a broad inclusion of any type of AIT might have led to the substantial heterogeneity of the results, particularly when there was no heterogeneity among studies performed by the same study group. The other possibility was the scoring systems for CSMS, symptom score and medication score used by Rondon et al. and Bozec et al. were different. Lastly, the included studies had risks of bias. They had high dropout rates and reporting bias. The number of participants in four RCTs was small which might also affect the accuracy of outcomes in this review. It is worthwhile to mention that no study evaluated the effect of AIT after discontinuation of treatment and only SCIT was studied in RCTs. Future studies with long-term follow-up and/or different forms of AIT (e.g. SLIT) are warranted in this respect.

\section{Conclusion}

Evidence from four RCTs and two observational studies supported the short-term effectiveness and safety of AIT for treating LAR. These short-term benefits included the improvements of combined symptom and medication score, symptom score, medication score, disease-specific quality of life, and slgG4. The sustained effects were inconclusive due to a lack of studies. There is a need for further studies of immunotherapy in LAR with measurement of long-term outcomes. The evidence of AIT in pediatric population is lacking. The effects of SLIT investigated by high-quality studies are required.

\section{Acknowledgements}

We thank Li Jia Yu for translation of a Chinese article.

\section{Authorship contribution}

MPH: study design, search, study selection, data collection, data analysis, drafting the article, and final approval. JS: search, study selection, data collection, revising the article, and final approval. KSe: search, study selection, data collection, revising the article, and final approval. WC: revising the article, and final approval. KSn: conception, study design, data analysis, drafting the article, and final approval.

\section{Conflict of interest}

Kornkiat Snidvongs received honoraria for speaking at symposia from Merck Sharp \& Dohme, Mylan, and Menarini. Minh P. Hoang, Jompol Samuthpongtorn, Kachorn Seresirikachorn, Wirach Chitsuthipakorn declare that they have no conflict of interest.

\section{Funding}

This is an unfunded project. 


\section{References}

1. Bachert C. Persistent rhinitis - allergic or nonallergic? Allergy. 2004; 59 Suppl 76: 11-15; discussion 15.

2. Bousquet J, Khaltaev N, Cruz AA, et al. Allergic Rhinitis and its Impact on Asthma (ARIA) 2008 update (in collaboration with the World Health Organization, GA(2)LEN and AllerGen). Allergy. 2008; 63 Suppl 86: 8-160.

3. Hamizan AW, Rimmer J, Alvarado R, et al. Positive allergen reaction in allergic and nonallergic rhinitis: a systematic review. Int Forum Allergy Rhinol. 2017; 7(9): 868-877.

4. Campo P, Eguiluz-Gracia I, Bogas G, et al Local allergic rhinitis: Implications for management. Clin Exp Allergy. 2019; 49(1): 6-16.

5. Powe DG, Jagger C, Kleinjan A, Carney AS Jenkins D, Jones NS. 'Entopy': localized mucosal allergic disease in the absence of systemic responses for atopy. Clin Exp Allergy. 2003; 33(10): 1374-1379.

6. Rondon C, Campo P, Togias A, et al. Local allergic rhinitis: concept, pathophysiology, and management. J Allergy Clin Immunol. 2012; 129(6): 1460-1467.

7. Huggins KG, Brostoff J. Local production of specific IgE antibodies in allergic-rhinitis patients with negative skin tests. Lancet. 1975; 2(7926): 148-150.

8. Rondon C, Dona I, Lopez S, et al. Seasonal idiopathic rhinitis with local inflammatory response and specific IgE in absence of systemic response. Allergy. 2008; 63(10) 1352-1358.

9. Rondon C, Romero JJ, Lopez S, et al. Local IgE production and positive nasal provocation test in patients with persistent nonallergic rhinitis. J Allergy Clin Immunol. 2007; 119(4): 899-905.

10. Eckrich J, Hinkel J, Fischl A, et al. Nasal lgE in subjects with allergic and non-allergic rhinitis. World Allergy Organ J. 2020; 13(6): 100129.

11. Sennekamp J, Joest I, Filipiak-Pittroff B, von Berg A, Berdel D. Local allergic nasal reactions convert to classic systemic allergic reactions: a long-term follow-up. Int Arch Allergy Immunol. 2015; 166(2): 154-160.

12. Rondon C, Campo P, Blanca-Lopez N, Torres MJ, Blanca M. More research is needed for local allergic rhinitis. Int Arch Allergy Immunol. 2015; 167(2): 99-100.

13. Rondon C, Campo P, Eguiluz-Gracia I, et al. Local allergic rhinitis is an independent rhinitis phenotype: The results of a 10-year follow-up study. Allergy. 2018; 73(2): 470-478.

14. Seidman MD, Gurgel RK, Lin SY, et al.
Clinical practice guideline: Allergic rhinitis. Otolaryngol Head Neck Surg. 2015; 152(1 Suppl): S1-43.

15. Durham SR, Gould HJ, Thienes CP, et al Expression of epsilon germ-line gene transcripts and mRNA for the epsilon heavy chain of IgE in nasal B cells and the effects of topical corticosteroid. Eur J Immunol. 1997; 27(11): 2899-2906

16. Moher D, Liberati A, Tetzlaff J, Altman DG, Group P. Preferred reporting items for systematic reviews and meta-analyses: the PRISMA statement. PLoS Med. 2009; 6(7): e1000097.

17. Dhami S, Nurmatov U, Arasi S, et al. Allergen immunotherapy for allergic rhinoconjunctivitis: A systematic review and meta-analysis. Allergy. 2017; 72(11): 1597-1631.

18. Pfaar O, Demoly P, Gerth van Wijk R, et al. Recommendations for the standardization of clinical outcomes used in allergen immunotherapy trials for allergic rhinoconjunctivitis: an EAACI Position Paper. Allergy. 2014; 69(7): 854-867.

19. Higgins JP, Altman DG, Gotzsche PC, et al. The Cochrane Collaboration's tool for assessing risk of bias in randomised trials. BMJ. 2011; 343: d5928.

20. Slim K, Nini E, Forestier D, Kwiatkowski F, Panis Y, Chipponi J. Methodological index for non-randomized studies (minors): development and validation of a new instrument. ANZ J Surg. 2003; 73(9): 712-716.

21. Wan X, Wang W, Liu J, Tong T. Estimating the sample mean and standard deviation from the sample size, median, range and/or interquartile range. BMC Med Res Methodol. 2014; 14: 135.

22. Review Manager (RevMan) [Computer program]. Version 5.4.1 Copenhagen: The Nordic Cochrane Centre: The Cochrane Collaboration; 2020.

23. Rondon C, Campo P, Salas M, et al. Efficacy and safety of D. pteronyssinus immunotherapy in local allergic rhinitis: a double-blind placebo-controlled clinical trial. Allergy. 2016; 71(7): 1057-1061.

24. Bozek A, Kolodziejczyk K, Jarzab J. Efficacy and safety of birch pollen immunotherapy for local allergic rhinitis. Ann Allergy Asthma Immunol. 2018; 120(1): 53-58.

25. Rondon C, Blanca-Lopez N, Campo P, et al. Specific immunotherapy in local allergic rhinitis: A randomized, double-blind placebo-controlled trial with Phleum pratense subcutaneous allergen immunotherapy. Allergy. 2018; 73(4): 905-915.

26. Bozek A, Winterstein J, Galuszka B, Jarzab
J. Different Development Forms of Local Allergic Rhinitis towards Birch. Biomed Res Int. 2020; 2020: 3408561

27. Rondon C, Blanca-Lopez N, Aranda A, et al Local allergic rhinitis: allergen tolerance and immunologic changes after preseasonal immunotherapy with grass pollen. J Allergy Clin Immunol. 2011; 127(4): 1069-1071.

28. Yin ZX, Mi Y, Zhai X. [Sublingual immunotherapy of Dermatophagoides farinae drops in nasal cavity local allergy]. Lin Chung Er Bi Yan Hou Tou Jing Wai Ke Za Zhi. 2019; 33(1): 75-79.

29. Gomez E, Campo P, Rondon C, et al. Role of the basophil activation test in the diagnosis of local allergic rhinitis. J Allergy Clin Immunol. 2013; 132(4): 975-976 e971-975.

30. Campo P, Villalba M, Barrionuevo E, et al. Immunologic responses to the major allergen of Olea europaea in local and systemic allergic rhinitis subjects. Clin Exp Allergy. 2015; 45(11): 1703-1712

31. Scadding GK, Scadding GW. Innate and Adaptive Immunity: ILC2 and Th2 Cells in Upper and Lower Airway Allergic Diseases. J Allergy Clin Immunol Pract. 2021; 9(5): 1851-1857.

32. Shamji MH, James LK, Durham SR. Serum immunologic markers for monitoring allergen-specific immunotherapy. Immunol Allergy Clin North Am. 2011; 31(2): 311-323.

33. Campo P, Eguiluz-Gracia I, Plaza-Seron MC, et al. Bronchial asthma triggered by house dust mites in patients with local allergic rhinitis. Allergy. 2019; 74(8): 1502-1510.

\author{
Kornkiat Snidvongs \\ Department of Otolaryngology \\ Faculty of Medicine \\ Chulalongkorn University \\ 1873 Rama 4 Road \\ Pathumwan \\ Bangkok 10330 \\ Thailand
}

Tel: (+66) 2-256-4103

Fax: (+66) 2-252-7787

E-mail:drkornkiat@yahoo.com 


\section{SUPPLEMENTARY MATERIAL}

Table S1. Search strategy.

\begin{tabular}{|c|c|}
\hline PubMed MEDLINE (625) & EMBASE (58) \\
\hline \#1 "desensitization, immunologic" [Mesh] & \#1 exp desensitization, immunologic/ \\
\hline \#2"immunotherapy" [Mesh] & \#2 exp immunotherapy/ \\
\hline \#3 "desensitization" [All Fields] & \#3 desensitization.mp. \\
\hline \#4 "oral immunotherapy" [All Fields] & \#4 oral immunotherapy.mp. \\
\hline \#5 "oral desensitization" [All Fields] & \#5 oral desensitization.mp. \\
\hline \#6"sublingual immunotherapy" [Mesh] & \#6 sublingual immunotherapy.mp. \\
\hline \#7" subcutaneous immunotherapy" [All Fields] & \#7 subcutaneous immunotherapy.mp. \\
\hline \#8 "allergen-specific immunotherapy" [All Fields] & \#8 allergen-specific immunotherapy.mp. \\
\hline \#9"epicutaneous immunotherapy" [All Fields] & \#9 epicutaneous immunotherapy.mp. \\
\hline \#10 "intradermal immunotherapy" [All Fields] & \#10 Intradermal Immunotherapy.mp. \\
\hline \#11 "intralymphatic immunotherapy" [All Fields] & \#11 intralymphatic immunotherapy.mp. \\
\hline \#12 "intranasal immunotherapy" [All Fields] & \#12 intranasal immunotherapy.mp. \\
\hline \#13 "specific immunotherapy" [All Fields] & \#13 specific immunotherapy.mp. \\
\hline \#14 "grazax" [All Fields] & \#14 grazax.mp. \\
\hline \#15 "ACARIZAX" [All Fields] & \#15 ACARIZAX.mp. \\
\hline \#16 "ALK-Abello" [All Fields] & \#16 ALK-Abello.mp. \\
\hline \#17 "odactra" [All Fields] & \#17 odactra.mp. \\
\hline \#18 "grastek" [All Fields] & \#18 grastek.mp. \\
\hline \#19“ragwitek" [All Fields] & \#19 ragwitek.mp. \\
\hline \#20 "pangramin plus" [[All Fields] & \#20 pangramin plus.mp. \\
\hline \#21 "Depigoid" [All Fields] & \#21 Depigoid.mp. \\
\hline \#22 "ALK SQ Depot" [All Fields] & \#22 ALK SQ Depot.mp. \\
\hline \#23 "Purethal" [All Fields] & \#23 Purethal.mp. \\
\hline \#24 "Chanllergen-Df" [All Fields] & \#24 Chanllergen-Df.mp. \\
\hline \#25 \#1 OR \#2 OR \#3 OR \#4 OR \#5 OR \#6 OR \#7 \#8 OR \#9 OR \#10 OR \#11 & \#25 \#1 OR \#2 OR \#3 OR \#4 OR \#5 OR \#6 OR \#7 \#8 OR \#9 OR \#10 OR \#11 \\
\hline OR \#12 OR \#13 OR \#14 OR \#15 OR \#16 OR \#17 OR \#18 OR \#19 OR \#20 OR & OR \#12 OR \#13 OR \#14 OR \#15 OR \#16 OR \#17 OR \#18 OR \#19 OR \#20 OR \\
\hline \#21 OR \#22 OR \#23 OR \#24 & \#21 OR \#22 OR \#23 OR \#24 \\
\hline \#26"local allergic rhinitis" [All Fields] & \#26 local allergic rhinitis.mp. \\
\hline \#27 "entopy" [All Fields] & \#27 entopy.mp. \\
\hline \#28 "entopic rhinitis" [All Fields] & \#28 entopic rhinitis.mp. \\
\hline \#29 \#26 OR \#27 OR \#28 & \#29 \#26 OR \#27 OR \#28 \\
\hline \#30 \#25 AND \#29 & \#30 \#25 AND \#29 \\
\hline \multicolumn{2}{|c|}{ Cochrane Library (21), Web of Science (53), ClinicalTrial.gov (4), Scopus (373), HTA (19) } \\
\hline \multicolumn{2}{|c|}{$\begin{array}{l}\text { \#1 ("immunologic, desensiti*" OR "immunotherapy" OR "oral immunotherapy" OR "oral desensitization" OR "sublingual immunotherapy" OR "subcu- } \\
\text { taneous immunotherapy" OR "epicutaneous immunotherapy" OR "intradermal immunotherapy" OR "intralymphatic immunotherapy" OR "intranasal } \\
\text { immunotherapy" OR "grazax" OR "ACARIZAX" OR "ALK-Abello" OR "odactra" OR "grastek" OR "ragwitek" OR "pangramin plus" OR "Depigoid" OR "ALK } \\
\text { SQ Depot" OR "Purethal" OR "Chanllergen-Df") }\end{array}$} \\
\hline \multicolumn{2}{|l|}{ \#2 ("local allergic rhinitis" OR "entopy" OR "entopic rhinitis") } \\
\hline$\# 1$ AND \# 2 & \\
\hline
\end{tabular}

Table S2. Risk of bias assessment of non-randomized studies using MINOR.

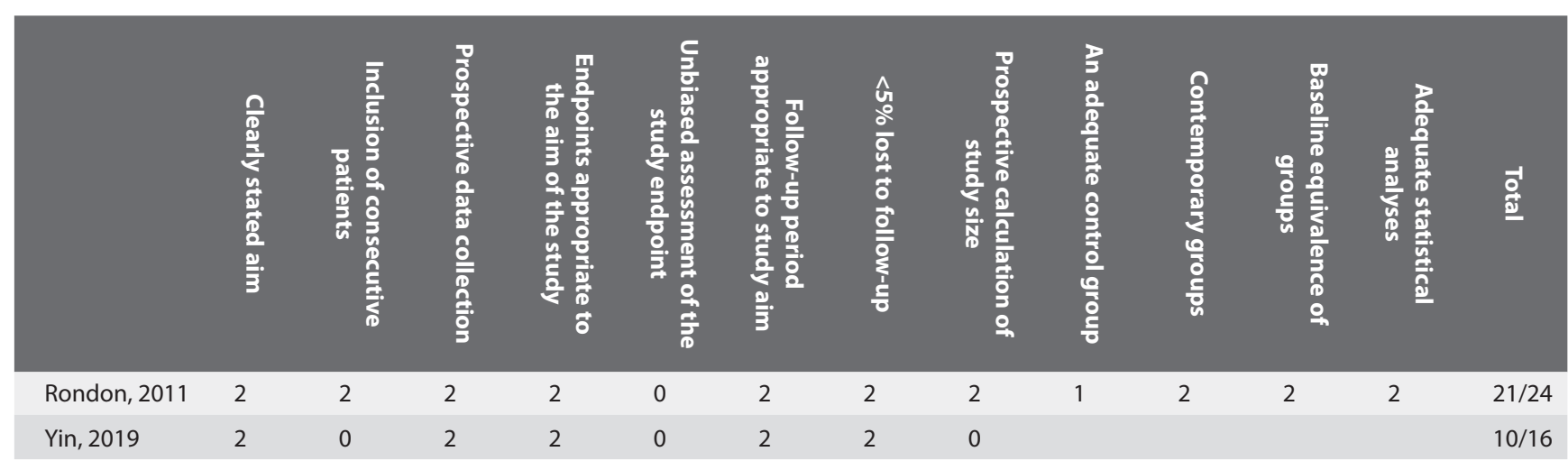

MINOR, methodological index for non-randomized studies 


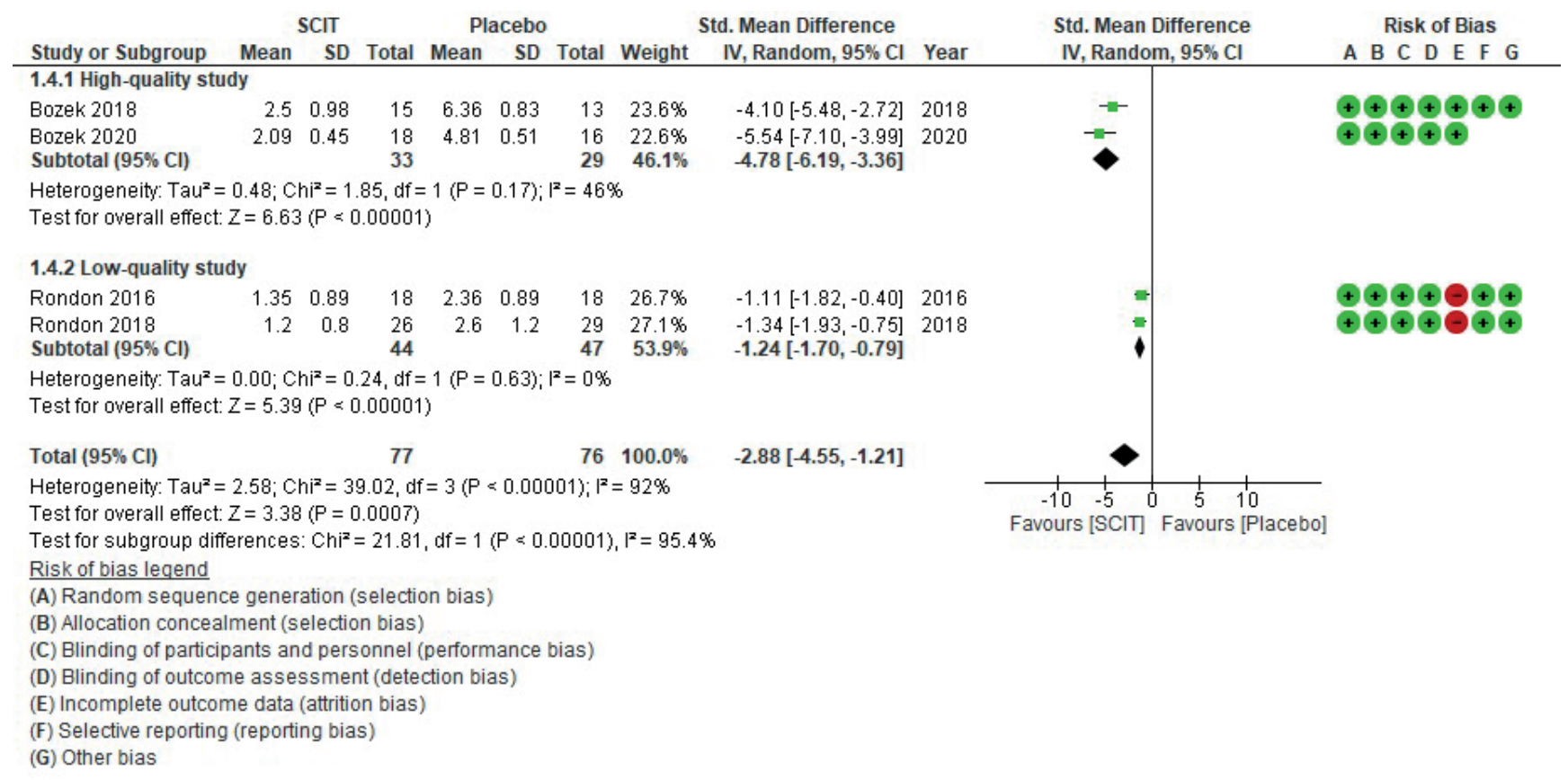

Figure S1. Short-term improvement in combined symptom and medication score and subgroup analysis by quality of study: subcutaneous immunotherapy versus placebo. $\mathrm{SCIT}=$ subcutaneous immunotherapy; $\mathrm{Cl}=$ confidence interval; $\mathrm{df}=$ degrees of freedom; $\mathrm{Std}$. mean difference $=$ standardized mean difference.

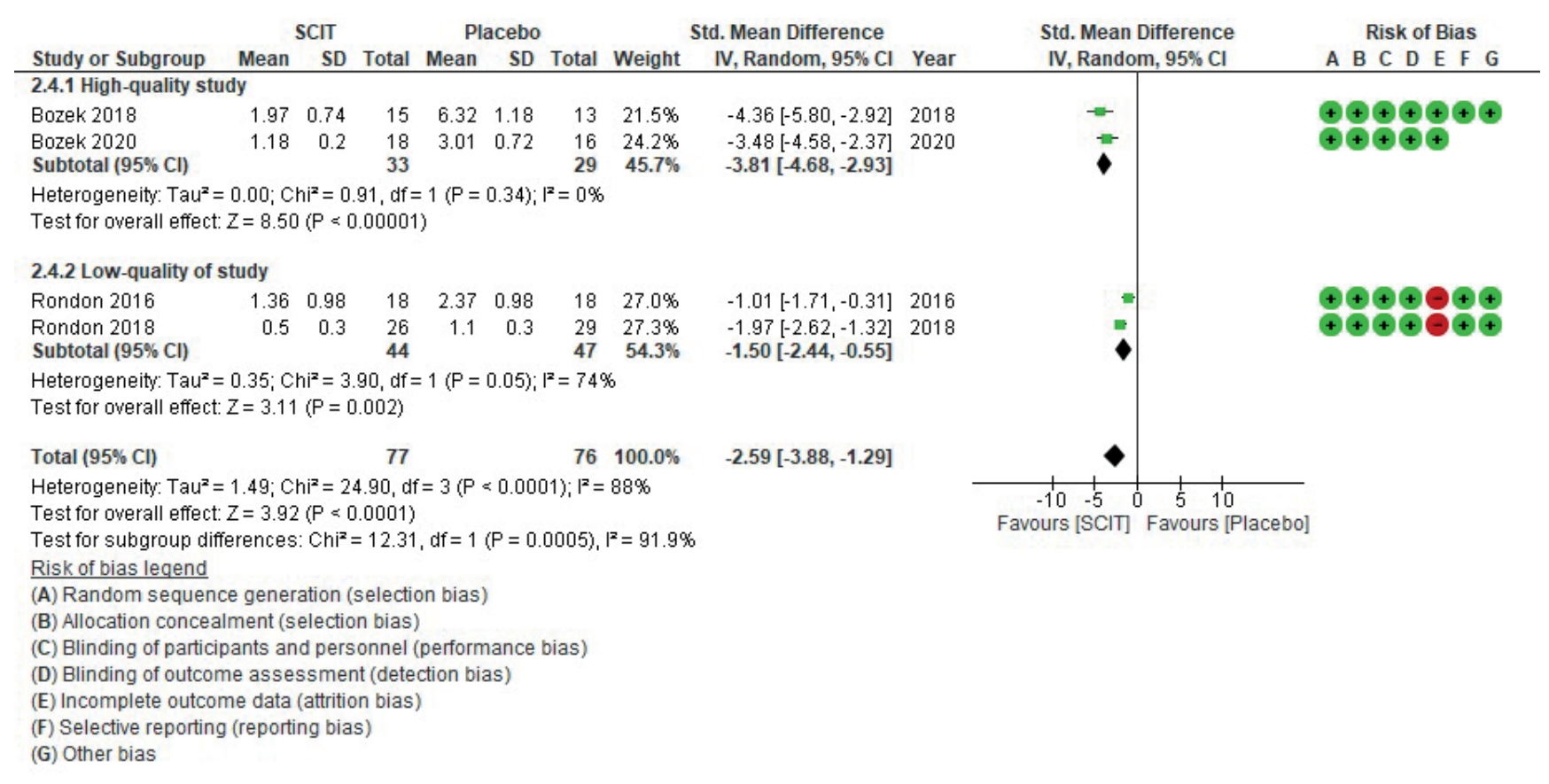

Figure S2. Short-term improvement in symptom score and subgroup analysis by quality of study: subcutaneous immunotherapy versus placebo. SCIT = subcutaneous immunotherapy $; \mathrm{Cl}=$ confidence interval; $\mathrm{df}=$ degrees of freedom; Std. mean difference = standardized mean difference. 


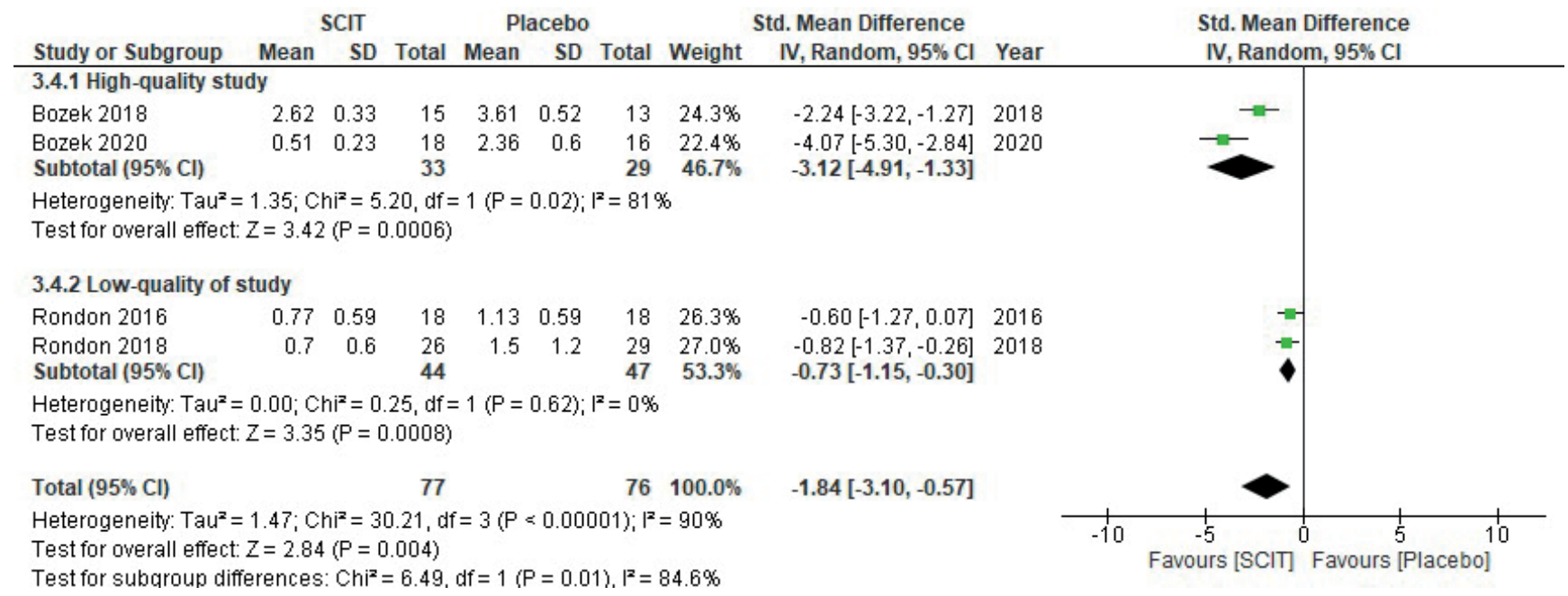

Figure S3. Short-term improvement in medication score and subgroup analysis by characteristic of rhinitis symptoms: subcutaneous immunotherapy versus placebo. $\mathrm{SCIT}=$ subcutaneous immunotherapy; $\mathrm{Cl}=$ confidence interval; $\mathrm{df}=$ degrees of freedom; $\mathrm{Std}$. mean difference $=$ standardized mean difference. 